\title{
Mitigation of repetitively flooded homes in New Orleans, Louisiana
}

\author{
N. J. Mattei, S. Stack, M. Farris, I. Adeinat \& S. Laska \\ University of New Orleans, \\ Center for Hazards Assessment, Response and Technology, USA
}

\begin{abstract}
Hurricane Katrina devastated a large portion of the City of New Orleans in 2005. Extensive long-term flooding was caused by failure of the hurricane protection system. However many residents of New Orleans are victims of repetitive flooding. This flooding is not due to levee failure and storm surge, but rather usually from heavy rainfall. This paper focuses on a project by the Center for Hazards Assessment, Response and Technology (CHART). CHART's objective is to support a sustainable Louisiana in light of natural, technological, and environmental risks. Teams of sociologists, engineers and urban planners assist in the development of best practices for reducing risks and in implementing these practices to achieve comprehensive community sustainability.

The specific project of interest focuses on working with small neighborhoods in the New Orleans area to help reduce the numbers of repetitive flood losses. This is done through an area analysis, outreach and education. A neighborhood is selected for an area analysis based on having a high density of repetitively flooded homes. The team works with the neighborhood association and the city council person representing the area. Planned drainage improvements are studied to assess the improvement's impact on the particular homes in the study area. In some cases, historic rain gage data is also used in this assessment. Repetitive loss homeowners answer a questionnaire about their flood experiences. Flood insurance claims are obtained. A series of neighborhood meetings are held with the objective of educating each individual owner as to their best flood mitigation plan.
\end{abstract}

Keywords: flood mitigation, floodplain management, repetitive flood loss. 


\section{Introduction}

The National Flood Insurance Program (NFIP) is continually faced with the task of paying claims while trying to keep the price of flood insurance at an affordable level. It has a particular problem with repetitive flood loss properties, which are estimated to cost $\$ 200$ million per year in flood insurance claim payments. Repetitive flood loss properties represent only 1 percent of all flood insurance policies, yet historically they account for nearly one-third of the claim payments (over $\$ 4.5$ billion to date). Mitigation of these repetitive flood loss properties will reduce the overall costs to the NFIP as well as to individual homeowners. The Federal Emergency Management Agency (FEMA) manages the NFIP.

\subsection{Repetitive flood loss}

FEMA defines mitigation as "any action taken to permanently eliminate or significantly reduce the long- term risk to human life and property from hazards and their effects through damage prevention and flood insurance", FEMA [1]. The most effective flood mitigation strategy involves mitigating structures that experience damage from multiple flood events and/or costly damage. FEMA identified two levels of losses that would be the target of mitigation efforts. A Repetitive Flood Loss Property is an NFIP-insured property where two or more claim payments of more than $\$ 1,000$ have been paid within a 10 -year period since 1978. To focus resources on those properties that represent the best opportunities for mitigation, a sub-category has been defined: Severe Repetitive flood loss Properties. A Severe Repetitive Flood Loss Property, as defined by the Flood Insurance Reform Act of 2004, is a 1-4 family residence that has had four or more claims of more than $\$ 5,000$ or two claims that cumulatively exceed the reported building's value. The Act creates new funding mechanisms to help mitigate flood damage for these properties.

\subsubsection{Center for Hazards Assessment, Response, and Technology (CHART)}

The University of New Orleans' Center for Hazards Assessment, Response and Technology (CHART) received a special grant from FEMA to collate data and analyze repetitive flood loss areas in Louisiana and, more recently, Texas. Using geographic information system (GIS) and flood insurance claims data, repetitive flood loss areas and properties are being prioritized for attention and analysis. In selected locations, CHART is reviewing whether flood control projects have been constructed or are planned that will reduce the repetitive flooding. These select areas are targeted for an area analysis.

\subsubsection{Reduction of repetitive flood loss - the process}

The objective of an area analysis is to help RL homeowners by providing a broader understanding of the flooding problems in their neighborhood and the potential solutions to the continual suffering that results from repetitive flooding. Informed homeowners can become their own advocates for change at the neighborhood, city, civil parish, state and even federal levels. An area analysis 
also reviews potential personal mitigation measures that are specifically relevant to homes found in the study area. Not all mitigation measures are appropriate for all homes. Possible funding options for certain mitigation options that are available to some homeowners are also identified. Again, the purpose of this effort is to educate the homeowners on what resources are potentially available for safeguarding their property and minimizing the risk of future flood loss.

Generally, this area analysis follows a FEMA-prescribed five-step process, FEMA [2]. However, the CHART team has enhanced the five-step process by adding two important steps: a preliminary step (the area selection process) and a final step (ongoing collaboration with the neighborhood), for a total of seven steps:

- Step 1.Select the area or neighbourhood to be studies

- Step 2.Advise all property owners in the target area of the analysis

- Step 3.Collect data on each building to determine the cause(s) of flooding

- Step 4.Ascertain feasible alternative mitigation

- Step 5.Contact agencies/organizations that may have plans that could affect the cause or impacts of the flooding

- Step 6.Document the findings and communicate them to the home owners

- Step 7.Conduct a follow-up with the community

\section{The area analysis process}

An area analysis is an approach to identify repetitive flood loss areas, evaluate mitigation approaches, and determine the most appropriate alternatives to reduce the risk of future repetitive flood damage.

\subsection{Step 1: select the area to be studied}

The CHART team selects several potential area analysis neighborhoods, using GIS data on repetitive loss and severe repetitive loss properties. The potential areas are selected based on several criteria. The area must have a high relative density, or cluster, of repetitive flood and severe repetitive flood loss properties. The team reviews repetitive flood loss claims data as well as other relevant information about residents of the area such as their interest in flood mitigation. This is done through a collaborative effort with local officials. Once a neighborhood is selected, a smaller subset of properties within the neighborhood is selected as the analysis area based on the aforementioned criteria, although the goal is to engage the entire neighborhood.

\subsection{Step 2: advise the stakeholders in the target area}

After an area is targeted for analysis, the next step is to advise the neighborhood about the project. It is desirable for a city or parish entity to send the notice. The locale's department of emergency management is usually appropriate. The notification letter sent to each homeowner is supplemented with a data sheet of survey questions, along with a stamped, addressed envelope. 


\subsection{Step 3: data collection}

The third step in the process is to collect relevant data on the problem, i.e., the properties exposed to flooding and the cause(s) of the repetitive damage. Five sources of information were used for this: flood studies, flood insurance data, drainage information, property owner-provided data, and on-site data collection. These data are collected through coordination with many agencies and departments.

\subsubsection{Flood studies}

Flood studies may include the city or parish's five-year plan, local drainage plan, project or studies, and large-scale drainage projects. Because the federal flood data dates to 1978, drainage projects that have been implemented since 1978 are included in the analysis as well as those under construction, in design or in the planning or study phase. FEMA's Flood Insurance Rate Map (FIRM) is also obtained for the target area. The FIRM is a federally provided document and corresponding map detailing the flood risk for a community. It shows the mapped floodplain, and is used in setting flood insurance rates. The regulatory floodplain used by FEMA for floodplain management and insurance aspects of the National Flood Insurance Program is based on the elevation of the 100-year flood. It may be easily misconstrued that the 100-year flood happens only once in 100 years. In actuality, the 100 -year flood has a $1 \%$ chance of occurring in any given year while the 10 -year flood has any $10 \%$ chance of occurring in a given year. An X zone is outside of the 100-year floodplain and has a lower risk of flooding. AE zones are Special Flood Hazard Areas (SFHA), meaning that the area has a high risk of flooding.

\subsubsection{Flood insurance data}

Federal agencies and mortgage lenders require flood insurance as a condition of financial aid or loans in Special Flood Hazard Areas (SFHA). However, many people located outside of SFHAs, in X zones, buy flood insurance voluntarily because of their experiences with or knowledge about the flood hazard. The CHART team obtains claims data from the appropriate FEMA region office for all repetitive flood loss properties in the study area. Claim information includes the date of each claim, dollar value of each claim, number of claims and average claim per property, and the estimated value and condition of the property.

It is likely that the data in this section underestimate the flooding problem because non-repetitive flood insurance claims data are not available to the team, NFIP records do not include claims data from before 1978, policy holders may not have submitted claims for smaller floods for fear of it affecting their coverage or their premium rates, and claim losses only account for items covered by the insurance policy (living expenses during evacuation, swimming pools, and automobiles are not covered by NFIP insurance).

\subsubsection{Drainage information}

Information is gathered about the watershed in which the target area is located. Tributaries and adjacent or nearby waterways and lakes are identified. Other 
pertinent drainage information includes GIS or hard data on subsurface storm drainage, open channels or canals, levees and pumping stations, if applicable. Was the flooding caused by rainfall, tropical storm or hurricane, storm surge, or a high tide? What were the dates of the flood events? Were the flood events in excess of the drainage system's design? Historical rain gage and stream gage data are collected for the dates of, prior to and immediately preceding each flood event. The condition of the drainage system is assessed. Information on the system's maintenance is obtained.

\subsubsection{Property owner data sheet}

A letter is sent to the residents living in the analysis area from the city or parish. It includes a data sheet. This data sheet offers the residents of the neighborhood the opportunity to explain their experiences with flooding, and to voice their concerns regarding flooding related issues. After reviewing the returned data sheets, CHART team members are able to direct the research so that it reflects those issues that are repeatedly raised by residents. The data sheet asks the resident about their specific home's history. Questions include:

- How long have you lived there?

- Has your property flooded?

- If so, what year?

- How deep did the floodwater get?

- What was the flood duration?

- What do you feel is the cause of the flooding?

- Ave you taken any flood protection measures?

- Do you have flood insurance?

\subsubsection{On-site data collection}

A team from CHART will visit the target analysis area and collect information on each property in the study area. The purpose of collecting these data is so that team members can gain a full understanding of all of the factors that contribute to the flooding problem. Data collected include the following:

- Whether or not the property was occupied.

- Single family or multi-family home.

- Type of foundation.

- Condition of foundation.

- Type of structure.

- Condition of structure.

- Number of stories.

- Estimation of the height of the first floor above grade.

- Estimation of the height of the adjacent grade above street.

- Presence of appurtenant structures such as garages or sheds.

- A photograph of each house.

In some cases, a survey of each property's lowest floor elevation will be undertaken. 


\subsection{Step 4: mitigation measures}

Knowing the drainage system, the flooding problem, and the types and condition of the buildings in the area leads to the fourth step in the area analysis procedure - a review of alternative approaches to protect properties from or reduce risk of future flood damage. Property owners should look at these alternatives but understand they are not all guaranteed to provide $100 \%$ flood protection. Seven approaches can be analyzed:

1. Acquisition of properties in the hazardous area.

2. Elevating the houses above the 100-year flood level.

3. Constructing small levees or floodwalls around one or more houses.

4. Dry flood proofing.

5. Development regulations.

6. Drainage improvements.

7. Purchasing flood insurance coverage on the building.

Each approach has its pros and cons, FEMA [3-6]. The first four measures are nonstructural approaches. Nonstructural approaches to mitigation involve modifying the building or lot so that floodwaters will not cause damage. They are implemented by the property owner and can be done on an individual property basis. All of the nonstructural measures require a building permit from the city.

\subsubsection{Acquisition or buy-out}

This measure involves buying one or more properties and clearing the site. If there is no building subject to flooding, there is no flood damage. Rarely is a whole community relocated. Acquisitions are usually recommended where the flood hazard is so great or so frequent that it is not safe to leave the structure on site. An alternative to buying and clearing the whole subdivision is buying out individual worst-case structures with FEMA funds. This approach would involve purchasing and clearing the lowest or the most severe repetitive flood loss homes. If FEMA funds are to be used, the applicant for FEMA must demonstrate that the benefits exceed the costs, using FEMA's benefit/cost software, the owner must be a willing seller, and the parcel must be deeded to a public agency that agrees to maintain the lot and keep it forever as open space.

Not everyone may want to sell their home, so a checkerboard pattern of vacant and occupied lots often remains after a buyout project, leaving "holes" in the neighborhood. The community must still pay for maintaining the streets, water lines, and other infrastructure to serve those who remain. The vacant lots must be maintained by the new owner agency, even though taxes are not paid on them. Often the parish does not look favourably on acquisition as mitigation.

\subsubsection{Elevation of the structure}

Raising the structure above the flood level is generally viewed as the best flood protection measure, short of removing the building from the floodplain. All damageable portions of the building and its contents are high and dry during a flood, which flows under the structure instead of into the house. Houses can either be elevated on piers or over a crawlspace. If a crawlspace is used, it is 
important to include vents that are appropriately sized: one square inch for each square foot of the building's footprint.

Most of the cost to elevate a building is in the preparation and foundation construction. Elevation is usually cost-effective for wood frame buildings on piers because it is easier to get lifting equipment under an already raised structure. Elevating a slab house is much more costly and disruptive. A FEMA grant may be obtained which pays $75 \%$ of the cost while the remaining $25 \%$ is paid by a non-Federal source. Federal funding support for an elevation project requires a study that shows that the benefits of the project exceed the cost. The applicant for funds must show that the ratio of the benefits over the costs is greater than one.

\subsubsection{Barriers}

Small floodwalls, levees, or berms can be constructed around one or more properties. Such barriers are not recommended for flood depths greater than three feet. Levees and berms are most appropriate for rural settings. Urban or suburban neighborhoods lack the yard space for such structures. However, small floodwalls are appropriate for suburban neighborhoods. An engineer should be consulted before beginning a floodwall project, and residents should contact the appropriate agency to acquire a permit.

Barriers require a method to close openings such as driveways. Generally, this requires human intervention, meaning someone needs to be available and have enough time to take action. Also required are relatively impervious soils to minimize seepage under the floodwall, a system to prevent sanitary sewer backup from flowing into the building, a system of drain tile (perforated pipes) that collects water that falls or seeps into the protected area and sends it to a collecting basin, a sump pump to send the collected water outside the barrier, and power to operate the sump pump around the clock during a storm. All barrier mitigation costs must be paid for by the owner.

\subsubsection{Dry floodproofing}

This measure keeps floodwaters out of a building. Walls are coated with waterproofing compounds or plastic sheeting. Openings (doors, windows, and vents) are closed, either permanently, with removable shields, or with sandbags.

A successful flood proofing project requires that the owner make exterior walls watertight by using a sealant or other means, provide closures for all the openings, including doors, windows, dryer vents and weepholes, and account for sewer backup and other sources of water entering the building (by use of a valve or drain plug). Even if the building is in sound condition, tests by the Corps of Engineers have shown that dry floodproofing should not be used for depths greater than 3 feet above floor level, as water pressure on the structure can collapse the walls and/or buckle the floor. There is usually no regulatory requirement to protect buildings up to the base flood elevation because the projects are less than substantial improvements. Floodproofing has its shortcomings as a flood protection measure. It usually requires human intervention, i.e., someone must be home to close the openings. Its success depends on the building's condition. It is very difficult to tell if there are cracks 
in the slab under the floor covering that will allow leakage. Periodic maintenance is required to check for cracks in the walls and to ensure that the waterproofing compounds do not decompose. The NFIP will not offer a lower insurance rate for dry floodproofed residences. All costs must be covered by the homeowner.

\subsubsection{Development regulations}

Many communities are regulated by a set of rules such as ordinances, deed restrictions, and neighborhood covenants that are intended to promote safety and order. These restrictions can be enforced at the city level, and/or at the neighborhood level. Such regulations must be reviewed by the team in order to determine their potential impact on flooding and on mitigation.

Many city or parish ordinances prescribe minimum requirements for land use and control measures for flood-prone areas. Definitions of substantial improvement may be given, often setting it at a repair, reconstruction, or improvement of a structure, the cost of which equals or exceeds $50 \%$ of the market value of the structure either, before the improvement or repair is started, or if the structure has been damaged and is being restored, before the damage occurred. Often new construction and substantial improvement of any residential structure are required to have the lowest floor, including basement, elevated at or above the base flood elevation. Sometimes freeboard is required. Therefore elevation above the base flood elevation at equal to the required freeboard as a mitigation measure is required by law for those buildings that are substantially damaged. If the cost of a flood protection project (especially when combined with other home remodeling work) exceeds $50 \%$ of the value of the house, the owner will have to elevate the structure to comply with this type of ordinance.

Many neighborhoods have bylaws and neighborhood covenants by which owners must abide. Regulating the development within a community is usually intended to help neighborhoods maintain a sense of solidarity and distinct character. In certain instances, these deed restrictions may hinder residents' plans for a mitigation project. Sometimes regulations that have been set in place over the decades may contribute to flooding. Deed restrictions that state that houses must have similar finished grade elevations can eliminate the ability of a homeowner to elevate their property. Additionally, the barring of a 'fence or wall' any nearer to the street than the building setback lines may prohibit the construction of small flood prevention floodwalls.

\subsubsection{Drainage or structural improvements}

Drainage problems that are a cause of repetitive flooding may be targeted by the city or parish for a drainage improvement project. Projects designed and constructed by the US Army Corps of Engineers can improve drainage on a large scale. Depending on the cause of flooding, projects such as channel improvements, increased pumping capacity of pump stations, channel diversions, increased capacity of storm water sewer systems, and construction of detention ponds may be implemented. These projects are often costly and may take years to move from a study phase, through design and finally into construction of a completed flood improvement project. 


\subsubsection{Flood insurance}

Although not a mitigation measure that reduces property damage from a flood, a National Flood Insurance Program policy has advantages. A flood insurance policy reduces a homeowner's financial damage due to surface flooding from the overflow of inland or tidal waters or from stormwater runoff. It is an excellent "backup" for a floodwall or elevation project where the flood is higher than the protection level. Usually repetitive, shallow, flooding is unlikely to reach conditions severe enough for a disaster declaration. Therefore, flood insurance may be the only source of assistance to help owners of damaged property pay for cleanup and repairs. As a mitigation measure, once a policy is in effect there is no need for human intervention (as is needed for some other mitigation measures). Coverage is available for the contents of a home as well as for the structure. Lastly, renters can buy contents coverage, even if the building owner does not buy coverage for the structure itself.

\subsection{Step 5: coordination}

There are many different agencies and organizations that should participate in a flood mitigation project for a study area. The list varies with the analysis area location. Possible agencies and organizations include the state and local Office of Emergency Management, the city or parish's public works, GIS, drainage and planning departments, the FEMA regional mitigation office, the local homeowner's association, state or parish flood control district, water development board, and the US Army Corps of Engineers.

\subsection{Step 6: findings}

Upon analysis of all data gathered, the team communicates the findings to the city or parish council person and other appropriate city/parish personnel. A neighborhood meeting of the homeowners is held to educate the homeowners as to the best mitigation methods available for each of their particular structures in the target area, with all stakeholders invited to join the discussion. Individual homeowners may schedule face-to-face or telephone consultations with the team. Ultimately it is the homeowner who must make the decision to mitigate. Homeowners and other stakeholders are given a draft area analysis report draft for comment. The final report is placed on CHART's website for easy public access.

\subsection{Step 7: follow-up}

In order to ascertain the impact of an area analysis, several follow-up analyses are planned. The follow-ups will include a second mailout data sheet and on-site survey of area properties in order to determine the impact that the area analysis had on flood mitigation in the target area. If flood events have occurred since mitigation implementation, the team will assess the success of the mitigation on eliminating or reducing flood damage. 


\section{Example area analysis: Metairie Cluster}

The Metairie Cluster is located in Jefferson Parish, Louisiana, near Lake Pontchartrain and adjacent to the Suburban Drainage Canal. The Metairie Cluster area was selected for analysis because it is representative of the Parish, in terms of types of structures and flooding problems as well as having a high concentration of repetitive flood properties. Of the 59 homes in the designated area, $16(27 \%)$ were repetitive loss properties and 5 of the $16(31 \%)$ are severe repetitive loss properties. The analysis was done in 2006, approximately one year after Hurricane Katrina flooded the New Orleans area. Of the 59 properties, 18 residents responded to the data sheet survey. The team noticed 7 "for sale" signs on homes in the target area during the on-site investigation.

\subsection{Metairie Cluster data}

The drainage system is typical of neighborhoods within New Orleans Hurricane Protection System and consists of storm sewer, open canals and pump stations that eventually pump stormwater into Lake Pontchartrain. The Suburban Canal and Pump Station directly drain the area. The area is designated an AE Zone on the Parish's FIRM and is completely within the 100-year floodplain, FEMA [7, 8].

The team found that a major structural mitigation improvement had begun construction, and once complete, would impact the area's drainage. The Southeast Louisiana Urban Flood Control Project (SELA), authorized by the US Congress in 1996 and undertaken by the US Army Corps of Engineers is a large drainage project that would enhance drainage in the Metairie Cluster area. According to the FEMA Flood Insurance Study in effect at the time of the analysis, the Base Flood Elevation (BFE), or 100-year flood level, of the neighbourhood was 3.7 feet below sea level. A hydraulic analysis of the drainage system post-SELA improvements yields a 100-year flood elevation of -5.20 feet. SELA lowers the 100-year flood elevation by 1.5 feet.

Flood claims for the analysis area totalled $\$ 1,844,839$ from $1978-2006$ for the 16 properties, with $\$ 734,578$ prior to Katrina and $\$ 1,110,261$ attributed to Katrina damage, FEMA [9]. The average payment prior to Katrina was $\$ 12,000$ and the average Katrina claim was $\$ 110,000$. The property owners' responses to the data sheets indicated that the level of the average pre-Katrina flood was $\sim 0.25$ feet and the Katrina level was $\sim 3.5$ feet. All 59 homes had slab foundations, all appeared to be in good condition. The CHART team shot top of first floor elevations and found that 13 structures were above the current BFE of -3.7 feet. All were found to be above the post-SELA 10-year flood elevation and 54 were found to be above the 100-year post-SELA flood elevation.

A review of the area's claims history shows that most flood events occurred prior to 1990 with the exception of the Katrina flood. Pre-Katrina floods were found to be primarily due to excessive rainfall, and not to tropical storms or hurricanes. The Katrina flooding of the Metairie Cluster in 2005 was NOT due to breaching of the levees of the Hurricane Protection System. The levees of 
Jefferson Parish were not breached or over-topped. Katrina flooding of the target area was found to be due to rainfall that was not pumped out of the drainage basin in a timely manner. A review of rain gage records found that rainfall levels from Katrina should not have caused the level of flooding that the area experienced. At the time of Katrina, the Parish's Emergency Management Plan required that all pump station operators be evacuated to higher ground in an adjacent parish until hurricane winds reached a safe level. The pumps were not functional during this time. Downed trees and power lines hampered efforts to return the operators to the stations. This delay contributed to the short term Katrina flooding experienced by the area.

The shallow flooding occurred due to rain events that happened between 1978 and 1995. Did the SELA improvements positively impact the area's drainage and thus mitigate the area? A review of rain gage data indicated that rain levels that did not cause flooding did occur after 1996 that were comparable to pre-1996 rain levels that did cause flooding, Ergen [10]. Investigation into the completed SELA contracts found that the first completed contracts for SELA-funded drainage improvements were for Suburban Canal and the Suburban Pump Station (both which directly drain the target area).

\subsubsection{Metairie Cluster findings}

Properties in the Metairie Cluster area were found to be subject to two types of flooding since 1978: shallow repetitive flooding due to inadequate drainage and deeper flooding caused by pump station failure during a catastrophic event (Katrina). Completion of SELA drainage improvement projects have yielded improved drainage of the area so that most homes (all but 5) are now above the 100-year flood elevation. The owners of the five at-risk homes were considering demo-rebuild to a higher elevation. Jefferson Parish has installed a safe-house at the Suburban Pump Station that will allow the pump station operator to stay at the site and operate the pump during hurricane wind events. The only other mitigation recommended was that owners maintain their flood insurance policies in order to mitigate the risk of the occurrence of a future catastrophic flood.

\section{Conclusions}

CHART has competed seven area analyses in Louisiana and Texas and has three others underway. Each area has unique causes of flooding. Flood mitigation must be tailored to the specific area, but also to the specific homes within the area. The mitigation method selected by a particular home owner is dependent of the level of risk that the owner is comfortable with.

Most home owners are not aware of the actual impact that planned or constructed drainage improvements will have on their specific property. Most are also unaware of nonstructural mitigation methods, even if the home has repetitively flooded. Although the choice of if and how to mitigate belongs ultimately to the home owner, an educated home owner will make a decision that better manages flooding risk. An area analysis can educate home owners in a neighborhood as to their particular best flood mitigation method. 


\section{References}

[1] FEMA, "Federal Emergency Management Agency History". Washington D.C., http://www.fema.gov/about/history.shtm

[2] FEMA, CRS Coordinator's Manual, 2006

[3] FEMA, Engineering Principles and Practices for Retrofitting Flood Prone Residential Buildings, FEMA-259, 1995

[4] FEMA, Homeowners Guide to Retrofitting: Six Ways to Protect Your House from Flooding, FEMA-312, 1998. http:/www.fema.gov/mit/frit

[5] FEMA, Protecting Building Utilities from Flood Damage, FEMA-348, 2000

[6] FEMA, Reducing Damage from Localized Flooding - A Guide for Communities, FEMA-511, 2005

[7] FEMA, Flood Insurance Rate Map, Jefferson Parish, March 23, 1995

[8] FEMA, Flood Insurance Study, Jefferson Parish, 1995

[9] FEMA, FEMA Region VI Repetitive flood loss data, National Data Collection Tool

[10] Ergen, E.C., Flood Mitigation Decision Tool for Target Repetitive Loss Properties in Jefferson Parish, Thesis, August 2006 